\title{
A Survey of Thyroid Gland Scintigraphy
}

\author{
Elpida S. Crawford, Daniel T. Guarasci, and Sheryl A. Larson
}

Nuclear Medicine Department, School of Medicine and Biomedical Sciences, University at Buffalo, Buffalo, New York

\begin{abstract}
The Society of Nuclear Medicine (SNM) published procedure guidelines for thyroid imaging in 1999. We wished to determine how many clinics performing thyroid imaging follow the guidelines and to what extent. Of particular interest to us was the choice of collimator. Methods: We developed a 10-question survey to obtain information on how hospitals perform thyroid imaging. The questions were designed to cover the procedure recommendations of the SNM guidelines. The survey was sent to 350 hospitals randomly selected from 11 states in the northeastern United States. Results: One hundred sixty-five surveys (47\%) were returned. Most of the clinics that responded obtain a history, hyperextend the neck, and obtain anterior and anterior oblique views. Twenty-five percent of the respondents obtain all their images with a parallel-hole collimator. Seventy-five percent use a pinhole collimator or a combination of parallel-hole and pinhole collimators. The number of counts and time used for acquiring the images vary greatly. Less than half the respondents palpate the neck for correlation with the scan. Conclusion: The survey results indicated that many clinics do not follow the recommendations of the SNM guidelines. The major deviations from the guidelines were in the choice of collimator, the number of counts or amount of time used to acquire images, and the lack of neck palpation for correlation with the scan.
\end{abstract}

Key Words: thyroid gland; imaging procedure; pinhole collimator

J Nucl Med Technol 2009; 37:173-178

DOI: $10.2967 /$ jnmt.108.060509

$\mathbf{T}$ he thyroid gland is located in the neck, superior to the trachea and between the thyroid cartilage and sternal notch. The gland is relatively small, consisting of 2 lobes, each of which is approximately $2-3 \mathrm{~cm}$ wide by $5 \mathrm{~cm}$ high. The 2 lobes are connected in the middle by the isthmus. The primary function of the thyroid gland is to synthesize, store, and secrete the thyroid hormones thyroxine and triiodothyronine. These hormones stimulate many metabolic processes, which are reflected by increased oxygen consumption and heat production. The synthesis and secretion of thyroid hormones is maintained by a feedback mechanism. Thyroidstimulating hormone is secreted by the pituitary gland and is regulated by the thyroid-releasing hormone produced in the

Received Nov. 24, 2008; revision accepted Apr. 8, 2009.

For correspondence or reprints contact: Elpida Sophia Crawford, University at Buffalo, 3435 Main St., 105 Parker Hall, Buffalo, NY 14214.

E-mail: esc@buffalo.edu

COPYRIGHT @ 2009 by the Society of Nuclear Medicine, Inc. hypothalamus. Thyroid-releasing hormone acts on the pituitary to release thyroid-stimulating hormone, which acts on the thyroid to increase all aspects of thyroid function. When the level of triiodothyronine and thyroxine in the blood rises, the level of thyroid-stimulating hormone falls because the hypothalamus produces less thyroid-releasing hormone, thus maintaining optimal thyroid function (1). Common thyroid disorders or problems include hyperthyroidism, hypothyroidism, inflammation of the thyroid, and thyroid cancer. Nuclear medicine plays a major role in the diagnosis and treatment of these conditions. Common indications for thyroid imaging include the evaluation of palpable nodules, evaluation of a gland abnormal to palpation but without nodules, evaluation of patients who had irradiation of the head and neck in childhood with or without palpable nodules, evaluation for ectopic thyroid tissue and lingual thyroid, and evaluation of congenital hypothyroidism.

The Society of Nuclear Medicine (SNM) published procedure guidelines for thyroid imaging in 1999 (2). The radiopharmaceuticals and doses for thyroid imaging recommended in the guidelines are listed in Table 1 . The guidelines recommend that the patient be supine and that the neck be extended by placement of a pillow under the shoulders. No fasting is required. A patient history should be taken and should include the results of thyroid function tests, the results of prior thyroid uptake and imaging tests, and mention of whether the patient had recently been administered radionuclides, had recently ingested iodine-rich foods, had undergone any prior iodinated-contrast procedures, might be taking interfering medications, or is pregnant or lactating.

The guidelines recommend that when ${ }^{99 \mathrm{~m}} \mathrm{Tc}$ is used, the anterior image be acquired for 100,000-200,000 counts or for $5 \mathrm{~min}$. When ${ }^{123} \mathrm{I}$ is used, the guidelines recommend anterior imaging for 50,000-100,000 counts or $10 \mathrm{~min}$. The thyroid should be palpated with the patient positioned for imaging. The views should include anterior and right and left anterior oblique. Radioactive markers should be used to identify anatomic landmarks and the location of palpable nodules. Duplicate views should be obtained without markers. For measuring the thyroid gland, sizing markers are useful but should be applied with caution since the pinhole collimator will cause geometric distortion with depth.

The purpose of the guidelines is to assist nuclear medicine practitioners in recommending, performing, interpreting, and reporting the results of thyroid scintigraphy. Regarding interpretation of the scans, the guidelines suggest 
TABLE 1

SNM Guidelines for Thyroid Imaging Radiopharmaceutical and Dose

\begin{tabular}{lr}
\hline Radiopharmaceutical & \multicolumn{1}{c}{ Dose } \\
\hline $131 \mathrm{I}$ & $50-200 \mu \mathrm{Ci}$ \\
$123 \mathrm{I}$ & $200-600 \mu \mathrm{Ci}$ \\
$99 \mathrm{mTC}$-pertechnetate & $2-10 \mathrm{mCi}$ \\
\hline
\end{tabular}

that localized findings on palpation should be marked on the neck of the patient so they can be correlated with the scintigraphic image. Information from ultrasound or other diagnostic imaging procedures should be available for comparison with the images obtained by radionuclide studies.

The SNM guidelines and most literature (2-4) recommend the pinhole collimator for routine thyroid imaging. Pinhole collimators, compared with parallel-hole collimators, offer improved spatial resolution for smaller organs such as the thyroid. The object is magnified and seen by a greater area of the detector, and the image is limited primarily by the intrinsic resolution of the $\gamma$-camera (Fig. 1). As the distance between the pinhole collimator and the source is increased, relative geometric efficiency drops rapidly (5). Therefore, a pinhole collimator can achieve superior system resolution and reasonable relative geometric efficiency at close distances (Fig. 2) (6). Thyroid imaging can be performed with a parallel-hole collimator, but the system resolution will not be as good as with a pinhole collimator at the same source-to-collimator distance. Zooming or magnifying parallel-hole images will not increase their resolution. As a result, small nodules in the thyroid may not be resolved (7).

Most clinics in western New York use a pinhole collimator for thyroid imaging. However, several use the parallel-hole collimator exclusively. This fact prompted us to conduct this study. The purpose of our study was to determine how many clinics perform thyroid imaging following the SNM guidelines and to what extent. Although inquiring about the choice
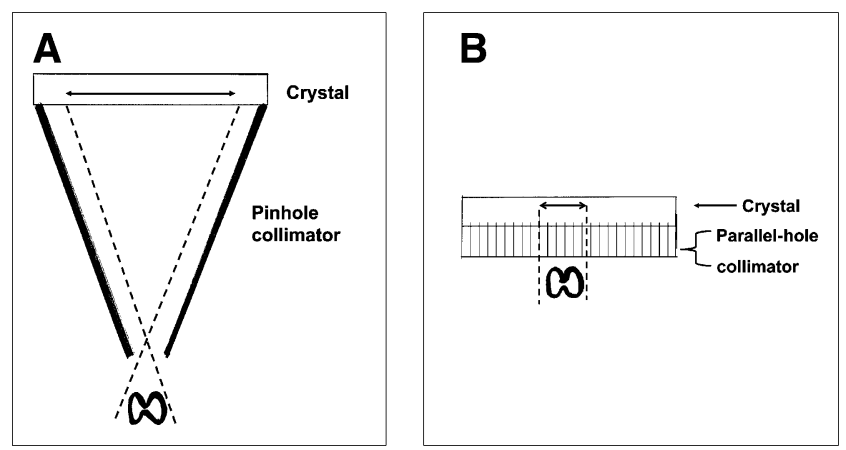

FIGURE 1. A larger area of the detector "sees" object when object is close to pinhole collimator $(A)$ than when object is close to parallel-hole collimator (B). of collimator was the main objective of the study, we designed a survey to inquire about other aspects of thyroid scintigraphy as well.

\section{MATERIALS AND METHODS}

A 10-question survey was designed to obtain information on thyroid imaging procedures. The questions were designed to cover the procedure recommendations of the SNM guidelines. The specific survey questions are listed in the Appendix.

The survey was sent to 350 hospitals with nuclear medicine departments, throughout the Northeast. The hospitals were randomly selected from the American Hospital Directory (www.ahd. com). The hospitals were located in 11 states, including New York, Pennsylvania, Michigan, Ohio, Connecticut, Vermont, Massachusetts, New Jersey, Virginia, North Carolina, and Maryland.

\section{RESULTS}

One hundred sixty-five surveys $(47 \%)$ were returned from hospitals in 10 different states whose number of beds ranged from 35 to 501, with an average of approximately 200. The survey results are listed in Table 2.

\section{Radionuclide}

One hundred seventeen of the 165 surveys returned (70.9\%) stated that ${ }^{123}$ I is used for thyroid imaging. Fortyone of the 165 (24.8\%) use ${ }^{99 \mathrm{~m}} \mathrm{Tc}$-pertechnetate for routine imaging.

\section{Dose}

Most clinics (85/165, or $51.5 \%$ ) performing thyroid imaging use a dose of between 200 and $299 \mu \mathrm{Ci}(1 \mathrm{Ci}=$ $37 \mathrm{GBq}$ ) of ${ }^{123} \mathrm{I}$ for thyroid imaging. The other 80 of 165 (48.5\%) used doses ranging from 100 to $599 \mu \mathrm{Ci}$ per patient. The 41 responders that use ${ }^{99 \mathrm{~m}} \mathrm{Tc}$-pertechnetate for patient dosing use a range from $400 \mu \mathrm{Ci}$ to $20 \mathrm{mCi}$, with the majority predominately using a $10-\mathrm{mCi}$ dose.

\section{Neck Positioning}

One hundred fifty-five, or $93.9 \%$, of respondents stated they hyperextended the neck during thyroid imaging. The other 10 did not answer this question on the survey.

\section{Fasting}

Sixty-seven of the 165 (40.6\%) reported having the patient fast before the examination. The number of hours of fasting ranged from 1 to 12 before patient dosing. Ninety-eight respondents (59.4\%) do not require the patient to fast.

\section{Patient History}

Nearly all respondents $(163 / 165$, or $98.8 \%)$ reported taking a patient history. Two (1.2\%) did not report that a patient history was taken.

\section{Views}

All respondents who answered the survey question on views reported taking an anterior view. The number of clinics that acquire oblique views was 151 of 165 (91.5\%). There were 149 clinics that reported using right and left 


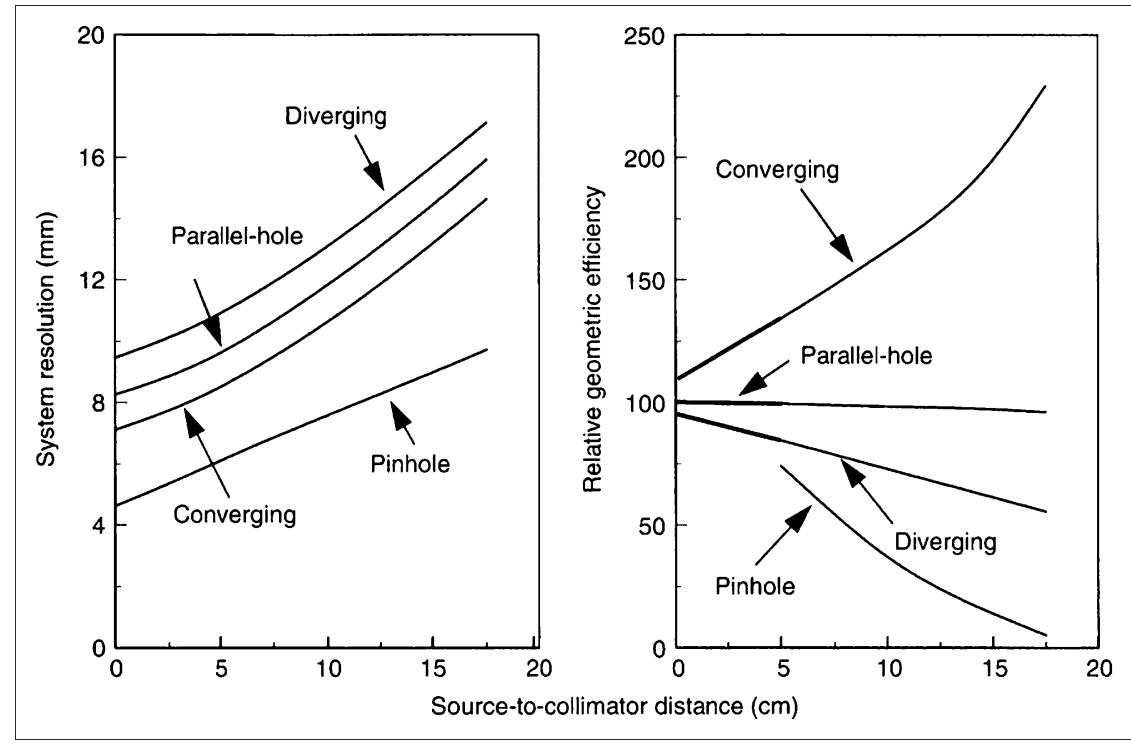

FIGURE 2. Performance characteristics of various collimators (5). anterior oblique views without markers and 2 clinics that reported taking oblique views with markers. Most respondents reported taking 2 anterior views-one with and one without markers. Thirty-seven, or approximately $23 \%$, reported taking only 1 anterior view with no markers. A smaller number $(13$, or $8 \%$ ) reported acquiring only 1 anterior view with markers.

\section{Counts Versus Time}

One hundred seventeen, or $70.9 \%$, of the clinics reported using ${ }^{123}$ I. Of those, 84 use only counts or time whereas 33 use both and end the acquisition by whichever is reached first. The counts that were reported ranged from 20,000 to more than 300,000 . Time termination ranged from 5 to 20 min. Of the clinics who responded, 41 of 165 , or $24.8 \%$, reported using ${ }^{99 \mathrm{~m}} \mathrm{Tc}$-pertechnetate. Thirty of the 41 reported using only counts or time, whereas 10 reported using both counts and time. The reported counts ranged from 50,000 to more than 300,000, and the reported time ranged from 5 to $10 \mathrm{~min}$.

\section{Measurement}

Only 72 of the 165 clinics reported using some type of method to size the gland. The reported methods include grid pictures, radioactive rulers, computer software, a ${ }^{57} \mathrm{Co}$ marker, ultrasound, and lead markers. Ninety-three of 165 , or $56.4 \%$, reported not using a method to size the gland.

\section{Collimator}

Regarding the type of collimator used, 107 of 165 (64.8\%) clinics reported using a pinhole collimator for imaging the thyroid, 42 of $165(25.5 \%)$ reported using a parallel-hole collimator, and 16 of $165(9.7 \%)$ use both pinhole and parallel-hole collimators.

\section{Neck Palpation}

Less than half the respondents, 67 of 165 (40.6\%), palpate the neck for correlation with the scan. Ninety-eight $(59.4 \%)$ reported that no palpation is performed.

\section{DISCUSSION}

Twenty-eight percent of the survey respondents use 99m Tc-pertechnetate exclusively for thyroid imaging. The SNM guidelines list the advantages and disadvantages of ${ }^{99} \mathrm{~m}$ Tc-pertechnetate and ${ }^{123} \mathrm{I}$-iodide for thyroid imaging (Table 3) (2). In addition to those items (Table 3), many publications have reported discordant results for thyroid nodules when imaged with these 2 different agents (8-11). Cold thyroid nodules seen on a ${ }^{123}$ I scan sometimes appear to accumulate ${ }^{99 \mathrm{~m}}$ Tc-pertechnetate. A cold nodule could be a thyroid carcinoma. Therefore, some thyroid cancers might be missed if thyroid imaging is done exclusively with 99m Tc-pertechnetate. Some publications recommend that if a ${ }^{99 \mathrm{~m}} \mathrm{Tc}$ pertechnetate thyroid scan shows warm or hot palpable nodules and the clinical indication is to rule out thyroid cancer, the scan should be repeated with ${ }^{123} \mathrm{I}$ (11).

Although the SNM guidelines for thyroid imaging do not recommend that patients fast before receiving the radiopharmaceutical, $41 \%$ of the respondents ask the patient to fast before receiving the ${ }^{123}$ I capsule. Fasting would have no effect on the absorption of ${ }^{99 \mathrm{~m}} \mathrm{Tc}$-pertechnetate since it is administered intravenously. However, the oral route of administration may cause ${ }^{123} \mathrm{I}$ absorption to vary from patient to patient. Pharmacokinetically, drugs that are administered orally are dependent on several factors for absorption. They include stomach contents, $\mathrm{pH}$ of stomach, and gastrointestinal motility. All 3 are patient-specific and could change if the stomach contains food or medications that affect one of the above factors (12). Therefore, the $41 \%$ of the respondents that recommend fasting to patients may 
TABLE 2

Survey Results

\begin{tabular}{|c|c|c|}
\hline Parameter & Number & Percentage \\
\hline Surveys sent & 350 & \\
\hline Surveys returned & 165 & 47.1 \\
\hline \multicolumn{3}{|l|}{$\begin{array}{l}\text { 1. Radionuclide routinely used for } \\
\text { thyroid imaging }\end{array}$} \\
\hline 123 & 117 & 70.9 \\
\hline 99mTc (pertechnetate) & 41 & 24.8 \\
\hline Both ${ }^{123}$ and ${ }^{99 m} \mathrm{Tc}$ & 6 & 3.6 \\
\hline $131 \mid$ & 1 & 0.6 \\
\hline \multicolumn{3}{|l|}{$\begin{array}{l}\text { 2. Routine dose administered } \\
123 \mid\end{array}$} \\
\hline $100-199 \mu \mathrm{Ci}$ & 11 & \\
\hline $200-299 \mu \mathrm{Ci}$ & 85 & \\
\hline $300-399 \mu \mathrm{Ci}$ & 9 & \\
\hline $400-499 \mu \mathrm{Ci}$ & 1 & \\
\hline $500-599 \mu \mathrm{Ci}$ & 2 & \\
\hline \multicolumn{3}{|l|}{ 99mTc (pertechnetate) } \\
\hline $5 \mathrm{mCi}$ & 3 & \\
\hline $7 \mathrm{mCi}$ & 1 & \\
\hline $8 \mathrm{mCi}$ & 1 & \\
\hline $10 \mathrm{mCi}$ & 28 & \\
\hline $10-15 \mathrm{mCi}$ & 2 & \\
\hline $20 \mathrm{mCi}$ & 1 & \\
\hline $0.4-0.5 \mathrm{mCi}$ & 2 & \\
\hline Did not answer & 20 & \\
\hline \multicolumn{3}{|l|}{ 3. Neck positioning } \\
\hline Neck hyperextended & 142 & 86.1 \\
\hline $\begin{array}{l}\text { Patient supine with neck extended } \\
\text { but not hyperextended }\end{array}$ & 13 & 7.9 \\
\hline Did not answer & 10 & 6.1 \\
\hline \multicolumn{3}{|l|}{ 4. Fasting required } \\
\hline Yes & 67 & 40.6 \\
\hline $1-3 \mathrm{~h}$ & 10 & 15 \\
\hline $4-6 \mathrm{~h}$ & 30 & 45 \\
\hline $7-9 \mathrm{~h}$ & 2 & 3 \\
\hline Overnight & 22 & 33 \\
\hline No & 98 & 59.4 \\
\hline \multicolumn{3}{|l|}{ 5. History taken } \\
\hline Yes & 163 & 98.8 \\
\hline No & 2 & 1.2 \\
\hline \multicolumn{3}{|l|}{ 6. Views routinely taken } \\
\hline Anterior view & 162 & \\
\hline 1 anterior view without markers & 37 & 22.8 \\
\hline 1 anterior view with markers & 13 & 8 \\
\hline $\begin{array}{l}2 \text { anterior views: } 1 \text { with and } 1 \\
\text { without markers }\end{array}$ & 112 & 69.1 \\
\hline $\begin{array}{l}\text { Oblique views in addition to } \\
\text { the anterior view }\end{array}$ & 151 & 93 \\
\hline $\begin{array}{l}\text { Right and left anterior oblique } \\
\text { without markers }\end{array}$ & 149 & \\
\hline $\begin{array}{l}\text { Right and left anterior oblique } \\
\text { with markers }\end{array}$ & 2 & \\
\hline Did not answer & 3 & \\
\hline \multicolumn{3}{|l|}{$\begin{array}{l}\text { 7. Method used to acquire anterior } \\
\text { view image }\end{array}$} \\
\hline \multicolumn{3}{|l|}{ Clinics using ${ }^{123} \mid$} \\
\hline \multicolumn{3}{|l|}{ Counts reported } \\
\hline $20,000-49,000$ & 11 & \\
\hline $50,000-74,000$ & 22 & \\
\hline $75,000-99,000$ & 1 & \\
\hline $100,000-149,000$ & 18 & \\
\hline $150,000-199,000$ & 2 & \\
\hline
\end{tabular}

TABLE 2 (continued)

Survey Results

\begin{tabular}{|c|c|c|}
\hline Parameter & Number & Percentage \\
\hline $200,000-300,000$ & 2 & \\
\hline $300,000+$ & 0 & \\
\hline \multicolumn{3}{|l|}{ Time reported } \\
\hline $5 \min$ & 22 & \\
\hline $7 \mathrm{~min}$ & 1 & \\
\hline $8 \mathrm{~min}$ & 6 & \\
\hline $10 \mathrm{~min}$ & 50 & \\
\hline $15 \min$ & 5 & \\
\hline $20 \mathrm{~min}$ & 3 & \\
\hline Other & 5 & \\
\hline Answered only counts or time & 84 & \\
\hline Answered both counts and time & 33 & \\
\hline \multicolumn{3}{|l|}{ Clinics using $99 \mathrm{~m} T \mathrm{c}$} \\
\hline \multicolumn{3}{|l|}{ Counts reported } \\
\hline $20,000-49,000$ & 0 & \\
\hline $50,000-74,000$ & 1 & \\
\hline $75,000-99,000$ & 0 & \\
\hline $100,000-149,000$ & 3 & \\
\hline $150,000-199,000$ & 6 & \\
\hline $200,000-300,000$ & 10 & \\
\hline $300,000+$ & 8 & \\
\hline \multicolumn{3}{|l|}{ Time reported } \\
\hline $5 \min$ & 12 & \\
\hline $10 \mathrm{~min}$ & 5 & \\
\hline $15 \min$ & 0 & \\
\hline $20 \mathrm{~min}$ & 0 & \\
\hline Other & 3 & \\
\hline Did not answer & 2 & \\
\hline Answered only counts or time & 30 & \\
\hline Answered both counts and time & 11 & \\
\hline \multicolumn{3}{|l|}{ 8. Method used to size gland } \\
\hline Yes & 72 & 43.6 \\
\hline No & 93 & 56.4 \\
\hline \multicolumn{3}{|l|}{ 9. Collimator used for imaging } \\
\hline Pinhole & 107 & 64.8 \\
\hline Parallel-hole & 42 & 25.5 \\
\hline Both & 16 & 9.7 \\
\hline \multicolumn{3}{|l|}{$\begin{array}{l}\text { 10. Neck palpated for correlation } \\
\text { with scan }\end{array}$} \\
\hline Yes & 67 & 40.6 \\
\hline No & 98 & 59.4 \\
\hline
\end{tabular}

*Many responses included count and time-whichever came first.

be trying to minimize these variables to ensure sufficient uptake of the radiopharmaceutical.

Most respondents take both anterior and oblique views. Markers on the images help to identify anatomic location. The SNM guidelines recommend that duplicate views be taken with and without markers. This recommendation ensures that markers, whether radioactive or nonradioactive, do not obstruct the view of any part of the thyroid. Some clinics use radioactive markers such as ${ }^{57} \mathrm{Co}$, and some clinics use nonradioactive markers. The recommended number of counts should be collected from the thyroid, not the thyroid plus markers. A substantial number of 
TABLE 3

Comparison of Radiopharmaceuticals for Thyroid Scintigraphy

\begin{tabular}{lll}
\hline \multicolumn{1}{c}{ Radionuclide } & Advantages & Disadvantages \\
\hline $99 \mathrm{~m}$ Tc-pertechnetate & Less expensive & Trapped but not organified \\
& More readily available & $\begin{array}{c}\text { Potentially misleading when activity is in } \\
\text { esophagus or vessels } \\
\text { Poor image quality when uptake is low }\end{array}$ \\
& $\begin{array}{l}\text { Shorter examination time } \\
\text { Better for visualization of } \\
\text { retrosternal thyroid tissue } \\
\text { Yields better images } \\
\text { when uptake is low }\end{array}$ & Higher cost \\
& & $\begin{array}{c}\text { Potentially less convenient for delayed } \\
\text { imaging at } 24 \mathrm{~h} \\
\end{array}$ \\
& & Less readily available \\
& Generally longer imaging times
\end{tabular}

clinics, $22.8 \%$, reported obtaining only views without markers. A smaller number of clinics $(8 \%)$ reported that only 1 anterior view is taken and that it is done with markers.

A major variable affecting image resolution is the number of counts acquired. Of the ${ }^{123} \mathrm{I}$ users that responded to question $7,20 \%(11 / 54)$ acquire less than the minimum recommended 50,000 counts. The recommended acquisition time for ${ }^{123} \mathrm{I}$ imaging is a minimum of $10 \mathrm{~min}$. Again, a significant number of ${ }^{123}$ I users $(29 / 90$, or $32 \%$ ) reported using an acquisition time of less than $10 \mathrm{~min}$.

The size of the thyroid gland is often a factor used in the determination of a therapy dose for hyperthyroidism $(3,4)$. Only $43.6 \%$ of the survey respondents reported a method to size the thyroid gland. We did not find this surprising as ultrasound can also be used to determine the size of thyroid lobes and nodules (13).

A large number of respondents $(25.5 \%)$ use a parallelhole collimator exclusively for imaging the thyroid. The exact reason was not identified but may be the cost of a pinhole collimator, the time required to change the collimator, or the lack of availability of a pinhole collimator for purchase with some camera models. During the data collection of this study, we discovered that a camera manufacturer had recommended to one clinic that a parallel-hole collimator be used for thyroid imaging.

\section{CONCLUSION}

The procedure used to obtain a thyroid scan varies from site to site. There is much deviation from the recommendations of the SNM guidelines. The greatest deviation from the guidelines occurs in the choice of collimation, the number of counts or amount of time used to acquire the images, and the lack of neck palpation for correlation with the scan.

The number of respondents exclusively using a parallelhole collimator was surprising. If manufacturers are recommending the parallel-hole collimator for thyroid imaging, this finding warrants further investigation. Have equipment improvements over the years eliminated the need for pinhole images of the thyroid gland? This is the question we are currently investigating.

Continuing education programs offered by professional organizations and societies tend to focus on newer procedures or technology. For commonly performed studies such as thyroid imaging, perhaps there is a need for regular continuing education that may reduce the amount of procedure variability. Our survey did not ask if the nuclear medicine clinic was accredited by the Intersocietal Commission for the Accreditation of Nuclear Medicine Laboratories or by the American College of Radiology. We wondered whether there would be as much variability in the way these studies are performed if the responding clinics were accredited. Accreditation serves to standardize procedures and reporting for optimal patient care.

\section{APPENDIX}

\section{Thyroid Imaging Method Survey}

1. Which radionuclide do you routinely (most often) use for thyroid imaging?

- ${ }^{123} \mathrm{I}$

- ${ }^{99 m}$ Tc-pertechnetate

2. What is the routine dose administered?

3. Explain how the neck is positioned for imaging.

4. Are patients required to fast prior to the radiopharmaceutical administration?

Circle Yes or No

If Yes, for how long?

5. Do you take a history prior to administering the radiopharmaceutical?

Circle Yes or No

6. How many views are routinely taken? Circle all that apply:

- anterior without markers

- anterior with markers

- right and left anterior oblique without marker

- right and left anterior oblique with markers

- other (please specify below) 
7. Is the anterior view image taken for counts or time? Please specify how long or how many counts:

8. Is a method used to size the thyroid gland (such as comparison with a grid picture, radioactive ruler, computer software for sizing the image)?

Circle Yes or No

If Yes, please describe the method used in the space below.

9. Which collimator(s) is/are routinely used for imaging the thyroid?

Circle one of the following:

- pinhole collimator only

- parallel-hole collimator only

- both pinhole and parallel-hole collimators (explain why)

10. Does someone in the imaging department palpate the patient's neck?

Circle Yes or No

If Yes

- Is the patient sitting up or lying down?

- Is palpating done before or after the images are taken?

- Are nodules felt marked on the images or correlated with what is seen on the images?

- Who palpates the neck?

\section{REFERENCES}

1. Drew HH, LaFrance ND, Chen JS. Thyroid imaging studies. J Nucl Med Technol. 1987;15:79-87.

2. Becker DV, Charkes ND, Hurley JR, et al. Society of Nuclear Medicine procedure guidelines for thyroid scintigraphy. In: Procedure Guidelines Manual. Reston, VA: Society of Nuclear Medicine; 2005:50-1-50-6.

3. Metler FA, Guiberteau MJ. Essentials of Nuclear Medicine Imaging. 5th ed. Philadelphia, PA: Saunders Elsevier; 2006:75-100.

4. Park HM. The thyroid gland. In: Henkin RE, Bova D, Dillehay GL, et al., eds. Nuclear Medicine. Vol 1. 2nd ed. Philadelphia, PA: Mosby Elsevier; 2006:790819.

5. Cherry DR, Sorenson JA, Phelps ME. Physics in Nuclear Medicine. 3rd ed. Philadelphia, PA: Saunders Elsevier; 2003:227-251.

6. Moyer RA. A low-energy multihole converging collimator compared with a pinhole collimator. J Nucl Med. 1974;15:59-64.

7. Goldsmith SJ. Endocrine system. In: Christain PE, Bernier DR, Langan JK, eds. Nuclear Medicine and PET: Technology and Techniques. 5th ed. St. Louis, MO: Mosby Co.; 2004:350-385.

8. Kusic Z, Becker DV. Saenger EL at el. Comparison of technetium-99m and iodine-123 imaging of thyroid nodules: correlation with pathologic findings. J Nucl Med. 1990;31:393-399.

9. dell'Erba L, Gerundini P, Caputo M, et al. Association of hyperfunctioning thyroid adenoma with thyroid cancer presenting as "trapping only" nodule at ${ }^{99} \mathrm{TcO}_{4}$-scintigraphy. J Endocrinol Invest. 2003;26:1124-1127.

10. Reschini E, Ferrari C, Castellani M, et al. The trapping-only nodules of the thyroid gland: prevalence study. Thyroid. 2006;16:757-762.

11. Okumura Y, Takeda Y, Sato S, et al. Differentiation of benign from malignant nodules by accumulation of ${ }^{99 \mathrm{~m}} \mathrm{Tc}$ pertechnetate using ${ }^{201} \mathrm{Tl}$ delayed scans. Clin Nucl Med. 1998;23:514-516.

12. Rowland M, Tozer, T. Clinical Pharmacokinetics: Concepts and Applications. 3rd ed. Media, PA: Lippincott Williams \& Wilkins; 1995:119-136.

13. Polyzos SA, Kita M, Avramidis A. Thyroid nodules: stepwise diagnosis and management. Hormones. 2007;6:101-119. 